\title{
Evaluación de la protección de una vacuna vectorizada contra la enfermedad de Gumboro bajo condiciones controladas en pollitas de postura comercial
}

\author{
Evaluation of the Protection of a vectorized vaccine against Gumboro disease \\ UNDER CONTROLLED CONDITIONS IN COMMERCIAL LAYING PULLETS
}

Nicol Lavado A. ${ }^{1}$, Eliana Icochea D., ${ }^{1,3}$, Rosa Perales C. ${ }^{2}$

\section{Resumen}

\begin{abstract}
Se evaluó la protección conferida por un programa de vacunación contra la enfermedad de Gumboro en pollitas de postura comercial que se les aplicó una vacuna vectorizada trivalente al primer día de edad por vía ocular. Se utilizaron 100 pollitas distribuidas en dos grupos de 50 aves. El grupo A vacunado con la vacuna trivalente y el grupo B no vacunado. A los 35 días de edad se realizó el desafío experimental con la cepa clásica F 52/70 del virus de Gumboro por vía ocular. Como indicadores de protección se evaluó la mortalidad, signos clínicos, lesiones macro y microscópicas bursales e índice bursal antes y después del desafío. Además, se evaluó la respuesta inmune en el día 1, 35 y 49 de edad mediante la prueba de ELISA y se compararon los parámetros productivos de ambos grupos. Las aves del grupo no vacunado presentaron $33.3 \%$ de mortalidad por Gumboro clínico, así como signos clínicos (diarrea y depresión) y lesiones macro y microscópicas más severos que los del grupo vacunado, en donde a los 10 días del desafío se observó una recuperación completa de signos clínicos sin mortalidad. Los valores del Índice Bursal de las aves del grupo B indicaron atrofia bursal a los 6 y 14 días pos-desafío, no así las del grupo A. Al día 35, previo al desafío, las aves del grupo A mostraron seroconversión de bajo nivel de anticuerpos maternales mientras que en las del grupo B no se detectaron anticuerpos $(\mathrm{p}<0.05)$. El grupo vacunado obtuvo mayor peso corporal, y mejor conversión alimenticia y uniformidad en relación con el grupo no vacunado $(\mathrm{p}<0.05)$. Se concluye que la vacunación de pollitas de postura con la vacuna vectorizada trivalente al primer día de edad induce eficiente protección contra la forma clínica de la enfermedad de Gumboro.
\end{abstract}

Palabras clave: virus de la enfermedad infecciosa de la Bursa; IBDV; vacuna vectorizada trivalente; efectos de protección; mortalidad

${ }^{1}$ Laboratorio de Patología Aviar, Facultad de Medicina Veterinaria, Universidad Nacional Mayor de San Marcos, Lima, Perú

${ }^{2}$ Laboratorio de Histología, Embriología y Patología Veterinaria, Facultad de Medicina Veterinaria, Universidad Nacional Mayor de San Marcos, Lima, Perú

${ }^{3}$ E-mail: micochead@unmsm.edu.pe

Recibido: 12 de octubre de 2017

Aceptado para publicación: 19 de mayo de 2018 
The protection conferred by a vaccination programme against Gumboro disease was evaluated in commercial laying pullets vaccinated with a trivalent vectorized vaccine applied at the first day of age via eye-drop. One hundred pullets distributed in two groups of 50 chicks were used. Group A vaccinated with the trivalent vaccine and group $B$ not vaccinated. At 35 days of age the birds were challenged with the classic strain F 52/70 of the Gumboro virus via ocular route. Mortality, clinical signs, macro and microscopic bursal lesions and Bursal index before and after the challenge were evaluated as protection indicators. In addition, the immune response was evaluated on day 1, 35 and 49 of age using the ELISA test and productive parameters of both groups were also compared. Birds of the unvaccinated group had $33.3 \%$ of clinical Gumboro mortality and clinical signs (diarrhea and depression) and macro and microscopic lesions more severe than those of the vaccinated group, and vaccinated birds did not show mortality and were fully recovered of clinical signs 10 days after the challenge. The values of the Bursal index of birds of group B indicated bursal atrophy at 6 and 14 days post challenge, but not those of group A. On day 35 (the day of the challenge), the birds of group A showed low seroconversion of maternal antibodies while group B no antibodies were detected $(\mathrm{p}<0.05)$. The vaccinated group obtained greater body weight, and better feed conversion and uniformity in relation to the unvaccinated group $(p<0.05)$. It is concluded that the vaccination of laying pullets with trivalent vectorized vaccine at the first day of age induces efficient protection against the clinical form of Gumboro disease.

Key words: infection bursitis disease virus; IBDV; trivalent vectorized vaccine; protection effects; mortality

\section{INTRODUCCIÓN}

La Enfermedad Infecciosa de la Bursa o Enfermedad de Gumboro es una amenaza para la industria avícola, una infección viral aguda, altamente contagiosa de pollos jóvenes, y considerada como la principal enfermedad inmunosupresora de las aves. Las aves se infectan después de las tres semanas de vida, y el impacto económico de la enfermedad depende de la forma de infección. En la forma clínica, las pérdidas son por mortalidad y disminución de la producción por la diarrea y depresión; mientras que, en la forma subclínica, el impacto económico está asociado a las consecuencias de la inmunosupresión como son la reducción de la capacidad para responder a las vacunaciones, la exacerbación de infecciones por otros agen- tes patógenos y el retraso del crecimiento (Ashraf, 2005; Eterradossi y Saif, 2013).

El virus de la enfermedad de Gumboro (IBDV - infection bursal disease virus) pertenece al género Avibirnavirus de la familia Birnaviridae. Su ARN es de doble cadena con dos segmentos (A y B), donde el segmento A codifica la proteína VP2 que contiene importantes sitios antigénicos para la neutralización y la respuesta inmune protectora (Van der Berg, 2000; Ashraf, 2005).

El virus se transmite rápidamente de un animal a otro por la vía oral, por contacto directo, a través de vectores inanimados, agua $o$ alimento contaminados con heces infectadas, y los pollos infectados excretan el virus hasta dos semanas pos-infección (Etienne, 2002). Los pollos infectados muestran 
inmunosupresión humoral y celular. La primera está asociada a la lisis de los linfocitos $\mathrm{B}$ que llevan inmunoglobulina $\mathrm{M}$ en su superficie, lo que conduce a la supresión severa de células B durante la fase aguda de la infección. Los mecanismos de inmunosupresión celular no están del todo dilucidados; sin embargo, se conoce que la proliferación mitogénica in vitro de células $\mathrm{T}$ de aves expuestas con IBDV está afectada (Sharma et al., 2000; Carballeda et al., 2011).

Los principales métodos de prevención y control son la bioseguridad y la vacunación a las reproductoras, pollos de engorde y pollas comerciales (Sarachai et al., 2010). La vacunación se basa en dos enfoques diferentes, uno es la protección de las aves jóvenes de la enfermedad subclinica mediante la inmunidad pasiva transmitida por la madre y el otro es la inmunidad activa utilizando vacunas vivas para la evitar la enfermedad clínica, donde el principal problema es determinar el tiempo adecuado de vacunación que permita la replicación adecuada del virus de la vacuna y que proteja a las aves de la enfermedad (Van der Berg et al., 1991; Jackwood, 2009; Banda, 2011).

En ponedoras comerciales, generalmente los planes de vacunación incluyen la aplicación de dos o tres vacunas de virus vivo intermedia durante la crianza (Saif, 2006; Villegas, 2009). Las pollitas de postura comercial son más susceptibles al virus de Gumboro por su genética y por ser de crecimiento lento, de allí que la inmunización debe cubrir su tiempo de vida productiva utilizando cepas vacunales de mayor patogenicidad que las usadas en pollos de carne. Por lo tanto, se requiere evaluar alternativas de vacunación como el uso de vacunas vectorizadas y determinar su nivel de protección (Perozo et al., 2010). El presente estudio tuvo por objetivo evaluar la protección conferida de una vacuna comercial vectorizada trivalente en pollas de postura comercial (enfermedad de Marek, laringotraqueitis infecciosa aviar y enfermedad de Gumboro).

\section{Materiales Y MéTodos}

\section{Lugar de Estudio}

La crianza y necropsias se realizaron en los ambientes de investigación y áreas del Laboratorio de Patología Aviar y los exámenes histopatológicos en el Laboratorio de Patología Veterinaria de la Facultad de Medicina Veterinaria (FMV) de la Universidad Nacional Mayor de San Marcos (UNMSM), ubicados en el distrito de San Borja en Lima, Perú.

\section{Animales y Vacunas}

Se emplearon 100 pollas de levante de postura comercial de un día de edad de la línea Hy-Line Brown, procedentes de un lote de reproductoras libre de enfermedades, Las aves fueron distribuidas en dos grupos experimentales (A y B). Las aves recibieron alimento concentrado comercial cubriendo requerimientos nutricionales de acuerdo con la edad de crianza y agua ad libitum. El periodo experimental fue de 49 días.

Se evaluó la protección contra la enfermedad de Gumboro de una vacuna vectorizada trivalente comercial (Farmune ${ }^{\circledR}$ ), que usa como vector al virus HVT de la enfermedad de Marek y que contiene las fracciones antigénicas de los virus de laringotraqueitis infecciosa aviar y de la enfermedad de Gumboro (VP2).

\section{Cepa de Desafío}

La cepa de desafío que se utilizó durante el estudio fue la cepa clásica del virus de Gumboro F52/70. 


\section{Diseño Experimental}

Se trabajó con dos grupos de 50 aves cada uno, con 6 repeticiones de 8 o 9 aves por grupo. El tamaño de muestra fue calculado para una diferencia de proporciones en dos grupos independientes, con nivel de significancia de 0.05 , obteniendo un mínimo de 44 aves por grupo. Las aves del primer grupo fueron vacunadas con la vacuna vectorizada trivalente $(\mathrm{HVT}+\mathrm{ILT}+\mathrm{IBD})$ aplicada por vía ocular el primer día de edad, y las aves del segundo grupo no fueron vacunadas contra la enfermedad de Gumboro, quedando como grupo control. Las aves de ambos grupos fueron desafiadas a los 35 días de edad por la ruta ocular, con una dosis de $30 \mu 1$ de la cepa F52/70, con un título de $10^{4} \mathrm{DIE}_{50}$.

\section{Parámetros Evaluados}

\section{Signos clínicos y mortalidad}

Las aves fueron examinadas clínicamente durante los 14 días siguientes al desafío registrándose la mortalidad, depresión y diarrea. Se realizó la necropsia a las aves muertas para determinar la causa de muerte.

\section{Evaluación de lesiones macroscópicas}

Se evaluó la ocurrencia de edema y hemorragias en la bursa de Fabricio y hemorragias musculares en cinco aves sacrificadas por grupo a los 35, 38, 41 y 49 días de edad.

El Índice Bursal (IB) determinó el grado de atrofia bursal, usando el criterio de interpretación descrito por Giambrone (1987) [(peso de la bursa / peso corporal) x 1000], donde: $1.5-3.5=$ bursa normal, $0.5-1.5=$ atrofia bursal y $<0.5=$ severa atrofia bursal. El índice bursal permitió determinar la inocuidad de la vacuna antes del desafío (35 días de edad), así como el grado de protección posdesafío a los 38, 41 y 49 días de edad.
Evaluación de las lesiones microscópicas

Las bursas colectadas fueron fijadas en formol al $10 \%$, teñidas con hematoxilinaeosina y examinadas al microscopio de luz. La evaluación se realizó mediante un sistema de valoración cualitativa de las lesiones de la bursa a nivel del epitelio de las plicas, folículos linfoides y tejido conectivo, con una calificación de daño bursal de 1 a 4 (Guzmán, 2010), donde:

- Grado $1=$ No se observan lesiones.

- Grado 2 = Se observa infiltración focal o difusa de heterófilos en lámina propia y el tejido interfolicular, disgregación de linfocitos interfolicular (edema), disminución leve de linfocitos.

- Grado 3 = Incluye las lesiones de grado 2. Además, se aprecia necrosis en la zona medular de los folículos y disminución de linfocitos en la zona de la corteza.

- Grado $4=$ Se aprecian lesiones de grado 3. Además, una marcada disminución de linfocitos, franca necrosis en médula, formación de quistes en folículos linfoides e incremento en el tejido interfolicular.

El valor final de las lesiones bursales de cada grupo se obtuvo sacando el promedio de las calificaciones de las bursas evaluadas.

\section{Respuesta serológica}

Se evaluó la respuesta inmune de anticuerpos contra el virus de la enfermedad de Gumboro mediante un kit de ELISA indirecto (Laboratorios IDEXX). En 15 aves por grupo se evaluó la inmunidad maternal al primer día de edad y la respuesta humoral a la vacunación previa al desafío (35 días de edad) y pos-desafío (49 días de edad). Los resultados serológicos se expresaron como promedio geométrico (PGT) con su respectivo coeficiente de variación $(\mathrm{CV})$.

\section{Parámetros productivos}

Se registró el peso corporal, uniformidad e índice de conversión alimenticia (ICA)- 


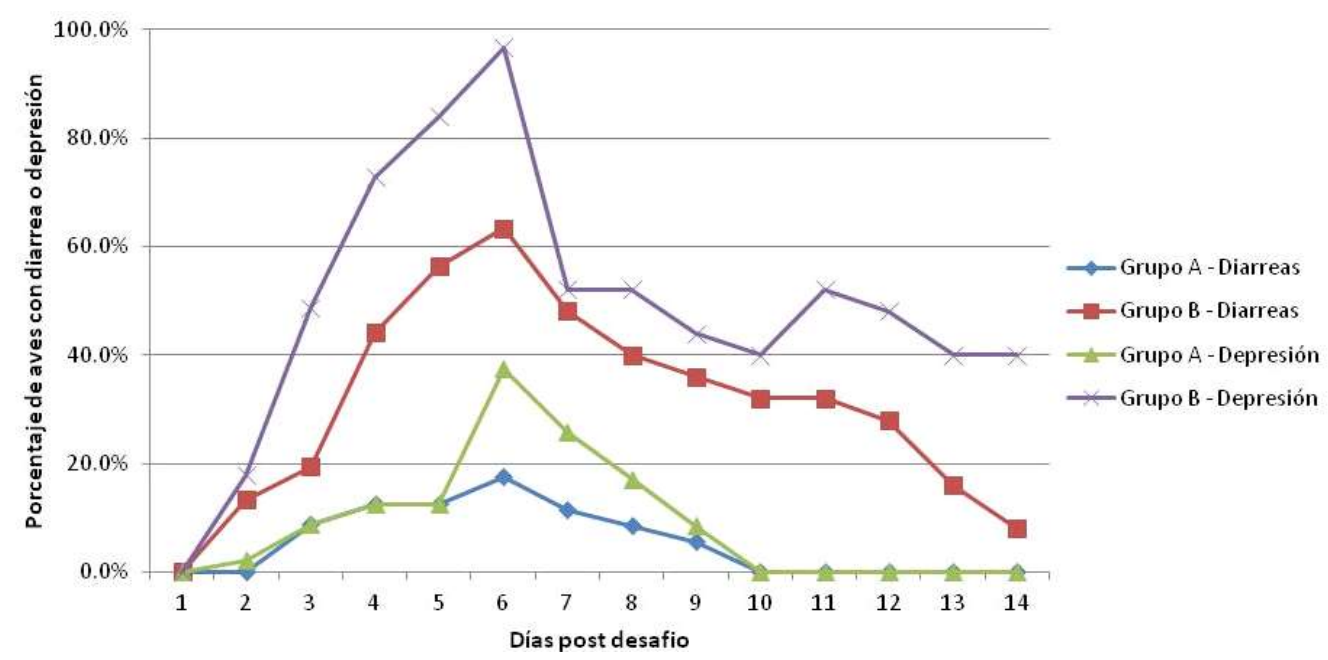

Figura 1. Frecuencia diaria (\%) de depresión y diarrea en pollitas de postura línea Hy-Line Brown, después del desafío con la cepa F52/70 hasta los 14 días pos-desafío

semanal y acumulada hasta los 49 días de edad. Para el cálculo de la uniformidad se determinó el peso promedio y se consideró un rango de $10 \%$, se contó el número de aves dentro del rango y se determinó su porcentaje dentro de la población total. E1 ICA se determinó dividiendo el consumo de alimento entre el peso corporal.

Para las mediciones del peso de las aves y del alimento se utilizó una balanza mecánica JBC, con capacidad máxima de $30 \mathrm{~kg}$ y nivel de precisión de $1 \mathrm{~g}$.

\section{Análisis Estadístico}

Se realizó la prueba de distribución $\mathrm{t}$ (de Student) para determinar diferencias significativas para las variables de índice bursal, niveles de anticuerpos y parámetros productivos. Para la evaluación de las lesiones histopatológicas de la bursa se realizó la prueba de U Mann Whitney. El análisis de las variables se realizó empleando el programa estadístico Stata 14.0.

\section{Resultados}

Solamente las aves del grupo control presentaron mortalidad a partir del segundo hasta el quinto día pos-desafío (pd), acumulando una mortalidad total de 33.3\% (15 aves). Los signos clínicos se presentaron a partir del día 2 pd en las aves de los dos grupos (vacunado y control), siendo más severos y de mayor duración en el grupo control (Figura 1). Los principales signos se caracterizaron por diarreas acuosas blanquecinas y depresión (Figura 2). La recuperación de las aves se inició a partir del día 6 pd. Las aves del grupo vacunado se recuperaron totalmente al día $10 \mathrm{pd}$, mientras que la recuperación del grupo control ocurrió luego de la última evaluación realizada a los 14 días pd.

Las principales lesiones pos-desafío fueron edema y atrofia de la bursa, siendo observadas en los días 3 y 6 pd. Las lesiones fueron severas, especialmente en el grupo control y leves en el grupo vacunado (Cuadro 1). Solo en la mortalidad presentada en 


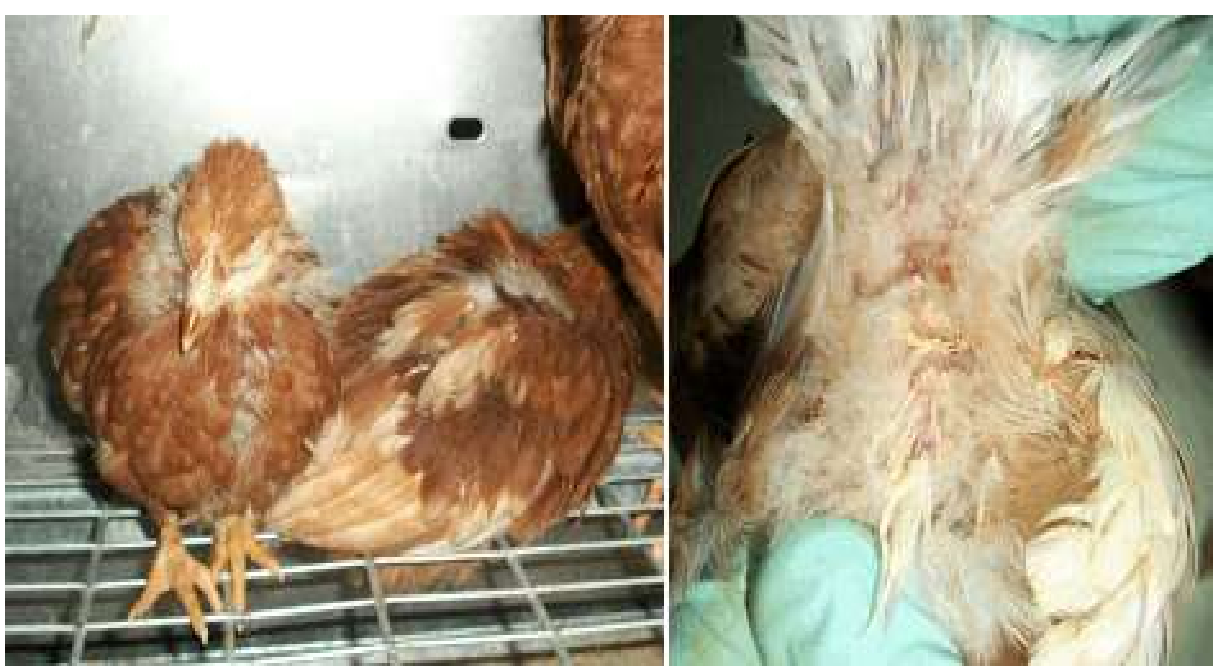

Figura 2. Signos clínicos de la enfermedad de Gumboro en pollas de levante de postura comercial. Izquierda: depresión; Derecha: diarrea

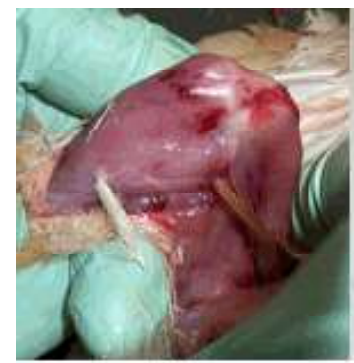

(A)

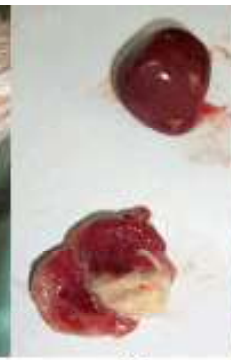

(B)

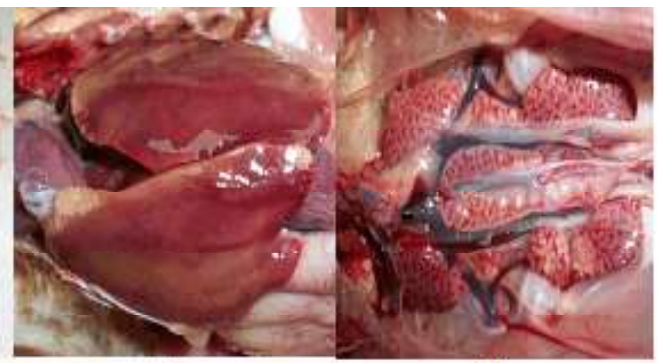

(C)
(D)

Figura 3. Lesiones en pollas del grupo control muertas pos-desafío con la cepa F52/70. (A) Hemorragias musculares; (B) Bursa hemorrágica y con material caseoso; (C) Necrosis hepáticas; (D) Uratosis renal

las aves del grupo control se observaron hemorragias bursales y material caseoso en el interior de la bursa en los primeros seis días $\mathrm{pd}$, además de hemorragias musculares en músculos, necrosis hepática y uratosis renal (Figura 3).

El IB de las aves de ambos grupos antes del desafío (35 días de edad) y hasta los 3 días pd estuvo dentro de los rangos de normalidad (1.5 a 3.5) y sin diferencias significativas entre grupos. En días posteriores se observó una disminución del índice bursal promedio en las aves del grupo vacunado a los 6 (1.71) y 14 (1.58) días pd, sin llegar a valores de atrofia bursal; por el contrario, las aves del grupo control mostraron valores de atrofia bursal a los $6(1.38)$ y 14 (0.99) días pd $(\mathrm{p}<0.05)$ (Cuadro 1).

Las aves del grupo vacunado presentaron un promedio de lesiones microscópicas en la bursa no mayores al grado 2 en todas las evaluaciones del estudio, mientras que las aves del grupo control solo presentaron un grado promedio de lesión menor a 2 previo al desafío, presentando lesiones de 3.6, $3.4 \mathrm{y}$ 2.8 a los 3, 6 y 14 días pd, respectivamente, evidenciándose en estas aves depleción linfoide, zonas de necrosis e infiltración de 
Cuadro 1. Promedio de Índice Bursal, número de aves con atrofia y edema bursal antes y después del desafío con la cepa F52/70 hasta los 14 días pos-desafío en pollitas de postura línea Hy-Line Brown vacunadas contra la enfermedad de Gumboro utilizando una vacuna vectorizada trivalente comercial

\begin{tabular}{ccccccccccccc}
\hline & \multicolumn{10}{c}{ Edad pos-desafío (días) } \\
\cline { 2 - 13 } Grupos & \multicolumn{1}{c}{ Índice bursal } & \multicolumn{1}{c}{ Atrofia bursal } & \multicolumn{3}{c}{ Edema bursal } \\
\cline { 2 - 13 } & 0 & 3 & 6 & 14 & 0 & 3 & 6 & 14 & 3 & 6 & 14 \\
\hline Vacunado & $3.58^{\mathrm{a}}$ & $3.01^{\mathrm{a}}$ & $1.71^{\mathrm{a}}$ & $1.58^{\mathrm{a}}$ & $0 / 5$ & $0 / 5$ & $1 / 5$ & $2 / 5$ & $0 / 5$ & $1 / 5$ & $2 / 5$ \\
Control & $3.42^{\mathrm{a}}$ & $2.89^{\mathrm{a}}$ & $1.38^{\mathrm{b}}$ & $0.99^{\mathrm{b}}$ & $0 / 5$ & $0 / 5$ & $4 / 5$ & $5 / 5$ & $0 / 5$ & $4 / 5$ & $5 / 5$ \\
\hline
\end{tabular}

$a, b$ Letras diferentes dentro de columnas indican diferencia estadística $(p<0.05)$

Cuadro 2. Calificación promedio de lesiones histopatológicas en bursas de Fabricio antes y después del desafío con la cepa F52/70

\begin{tabular}{lcccc}
\hline \multirow{2}{*}{ Grupo $\begin{array}{c}\text { Pre-desafío } \\
(35 \text { días })\end{array}$} & \multicolumn{3}{c}{ Días pos-desafío } \\
\cline { 2 - 5 } & & 3 & 6 & 14 \\
\hline $\mathrm{A}$ & $2.0^{\mathrm{a}}$ & $1.8^{\mathrm{a}}$ & $1.6^{\mathrm{a}}$ & $2.0^{\mathrm{a}}$ \\
$\mathrm{B}$ & $1.8^{\mathrm{a}}$ & $3.6^{\mathrm{b}}$ & $3.4^{\mathrm{b}}$ & $2.8^{\mathrm{a}}$ \\
\hline $\mathrm{a}, \mathrm{b}$ & Letras diferentes dentro de columnas indican \\
diferencia estadística ( $\mathrm{p}<0.05)$ \\
A: vacunado al primer día de edad; $\mathrm{B}$ : no \\
vacunado
\end{tabular}

heterófilos y macrófagos, edema intersticial y formaciones quísticas. La diferencia del grado de lesiones entre grupos los días 3 y 6 pd fueron estadísticamente significativas $(\mathrm{p}<0.05$, Cuadro 2$)$.

Los títulos de anticuerpos maternales de las aves de ambos grupos fueron similares, indicando un moderado nivel y buena uniformidad de protección pasiva en el lote. Al día 35 de edad (día del desafío), los anticuerpos de las aves del grupo vacunado disminuyeron a niveles bajos, mientras que no se detectaron anticuerpos en las aves del grupo control $(\mathrm{p}<0.05)$. A los 49 de edad (14 días pd), ambos grupos tuvieron un aumento en los niveles de anticuerpos (Cuadro 3).

Los pesos corporales, la uniformidad y el ICA fueron similares en los dos grupos durante el periodo de crianza previo al desafío. Posterior al desafío (35-49 días de edad), el peso promedio fue considerablemente mayor en las aves del grupo vacunado en comparación a las aves del grupo control, siendo estadísticamente diferente en la semana 7 $(\mathrm{p}<0.05)$. Además, las aves del grupo vacunado mantuvieron buena uniformidad e ICA a diferencia del grupo control (Cuadro 4).

\section{Discusión}

Van der Berg et al. (1991) consideran el criterio de mortalidad en pollas de postura como un criterio absoluto para medir la efectividad de las vacunas, mientras que en broilers consideran la mortalidad como un criterio relativo, especialmente debido a la mayor susceptibilidad de las aves de postura por sus características genéticas y de crecimiento lento. La mortalidad en estas aves puede llegar al $60 \%$ con cepas muy virulentas (Van der Berg et al., 1991; Nielsen et al., 1998; Saif, 2003; Di Fabio, 2006). La mortalidad en el presente estudio fue nula en el grupo vacunado y de $33.3 \%$ en el grupo con- 
Cuadro 3. Títulos de anticuerpos por ELISA antes y después del desafío con la cepa F52/70 hasta los 14 días pos-desafío en pollitas de postura línea Hy-Line Brown vacunadas contra la enfermedad de Gumboro utilizando una vacuna vectorizada trivalente comercial

\begin{tabular}{cccccc}
\hline \multirow{2}{*}{ Desafío } & \multirow{2}{*}{\begin{tabular}{c} 
Edad \\
\cline { 3 - 6 }
\end{tabular}} & \multicolumn{2}{c}{ Vacunado } & \multicolumn{2}{c}{ Control } \\
\cline { 3 - 6 } Antes & 1 & $2190^{\mathrm{a}}$ & 32.9 & $2159^{\mathrm{a}}$ & 24.5 \\
& 35 & $369^{\mathrm{a}}$ & 56.4 & $139^{\mathrm{b}}$ & 71.9 \\
Después & 49 & $5095^{\mathrm{a}}$ & 23 & $4920^{\mathrm{a}}$ & 25.3 \\
\hline
\end{tabular}

a,b Letras diferentes dentro de columnas indican diferencia estadística $(p<0.05)$

PGT: Promedio geométrico; CV\%: coeficiente de variación

Cuadro 4. Peso corporal, uniformidad e índice de conversión alimenticia (ICA) semanal antes y después del desafío con la cepa F52/70 hasta los 14 días pos-desafío

\begin{tabular}{cccccccc}
\hline \multirow{2}{*}{ Desafío } & Edad & \multicolumn{2}{c}{ Peso corporal $(\mathrm{g})$} & \multicolumn{2}{c}{ Uniformidad (\%) } & \multicolumn{2}{c}{ ICA } \\
& (días) & Vacunado & Control & Vacunado & Control & Vacunado & Control \\
\hline \multirow{6}{*}{ Antes } & 1 & 36.8 & 37.2 & 82.3 & 84.7 & & \\
& 7 & 67.3 & 68.6 & 88.1 & 89.9 & 1.04 & 1.02 \\
& 14 & 110.5 & 120.5 & 89.7 & 91.3 & 1.77 & 1.62 \\
& 21 & 173.6 & 178.4 & 91.6 & 91.6 & 1.99 & 1.93 \\
& 28 & 243.3 & 248.6 & 92.5 & 93.1 & 2.18 & 2.13 \\
& 35 & 336.7 & 338.3 & 93.4 & 93.7 & 2.20 & 2.19 \\
\hline \multirow{2}{*}{ Posterior } & 42 & 374.4 & 337.7 & 90.3 & 67.8 & 2.35 & 2.49 \\
& 49 & $436.9^{\mathrm{a}}$ & $371.8^{\mathrm{b}}$ & 89.9 & 64.2 & 2.35 & 2.58 \\
\hline
\end{tabular}

${ }^{a, b}$ Letras diferentes entre filas dentro una misma variable indican diferencia estadística $(p<0.05)$

trol; siendo similar al estudio de Perozo et al. $(2009,2010)$ con una vacuna vectorizada similar a la usada en este estudio, pero utilizando aves SPF y pollos de engorde.

Los dos grupos presentaron signos clínicos compatibles con la enfermedad posterior al desafío: sin embargo, los signos fueron severos en el grupo control y leves en el grupo vacunado, especialmente cuadros de depresión y diarrea, similares a los reportados por Rauw et al. (2007) y Eterradossi y Saif (2013).
Los dos grupos presentaron lesiones bursales pos-desafío, observándose solo leve edema de la bursa en las aves del grupo vacunado, mientras que las aves del grupo control presentaron severo edema, atrofia de la bursa, hemorragias bursales y presencia de material caseoso en el interior de la bursa. Estas lesiones concuerdan con las observadas por otros autores (González et al., 2005; Harris, 2010; Eterradossi y Saif, 2013), quienes mencionan que al segundo o tercer día pos-infección se presenta un aumento de ta- 
maño y peso de la bursa de Fabricio debido al edema e hiperemia, donde hacia el cuarto día suele duplicar su peso y tamaño, para luego disminuir y ocurrir la atrofia. Otras lesiones observadas solamente en el grupo control fueron hemorragias musculares, necrosis hepática y uratosis renal; resultados similares a los descritos por Van Den Berg (2000), Guadarrama et al. (2009) y Eterradossi y Saif (2013).

El valor promedio del índice bursal del grupo vacunado se mantuvo dentro de los rangos normales $(>1.5)$, mientras que el grupo control fue reduciéndose hasta llegar a niveles de atrofia en los días 6 y 14 pos-desafío (1.38 y 0.99 , respectivamente). Este resultado evidencia que la vacuna usada indujo protección y adecuada inmunocompetencia en las aves vacunadas, tal y como ha sido reportado (Perozo et al., 2009, 2010).

Se conoce que el órgano blanco de una vacuna vectorizada como la usada en este estudio no es la bursa ni los linfocitos B inmaduros, pues el virus vector es un herpesvirus al que se le insertó el gen que codifica la VP2 del virus de Gumboro. La patogenia y patrón de replicación viral es de los herpesvirus y, en consecuencia, no se produce daño tisular atribuible a la vacunación como si se observa con las vacunas vivas que contienen el virus completo y ocasionan daño bursal de moderado a severo. Por ello, las aves del grupo vacunado no presentaron lesiones significativas antes del desafío, ni atrofia bursal. Posterior al desafío, las lesiones histopatológicas predominantes en todas las evaluaciones realizadas fueron las necrosis y la depleción linfoide en la bursa, especialmente en el grupo no vacunado, lo que demuestra que las aves del grupo control carecían de protección contra la enfermedad de Gumboro. Este comportamiento concuerda con hallazgos previos (Butcher y Miles, 1995; Ashraf, 2005; Perozo et al., 2009, 2010).

El promedio de los títulos de anticuerpos maternales al primer día de edad, previo a la vacunación, fue como se esperaba, de un ni- vel intermedio y uniformidad buena, ya que las reproductoras tienen un programa de vacunas vivas e inactivadas que aseguran la trasmisión de anticuerpos a la progenie en cantidad y uniformidad adecuadas (Saif, 2006; Villegas, 2009; Banda, 2011). En el día del desafío (35 días de edad) se detectó un bajo nivel de anticuerpos en 6/15 aves del grupo vacunado debido a que la vacuna vectorizada induce una respuesta más celular que humoral, en tanto que a los 14 días del desafío se observó un aumento de los anticuerpos en los dos grupos, evidenciando seroconversión en respuesta al desafío.

Las aves del grupo vacunado obtuvieron la mayor ganancia de peso, mejor uniformidad y mejor ICA (436.9 g, $89.9 \%$ y 2.35 , respectivamente) en comparación a las del grupo control (371.8 g, 64.2\% y 2.58 , respectivamente), mostrando estar protegidas de la enfermedad clínica y de la afectación de los parámetros productivos como consecuencia de los signos de depresión y diarrea ocasionados por la cepa patogénica en el grupo control no vacunado.

\section{Conclusiones}

La vacuna vectorizada aplicada en pollitas de postura demostró proteger eficientemente a las aves de la forma clínica de la enfermedad de Gumboro, al haberse obtenido una viabilidad de $100 \%$, signos clínicos y lesiones macro y microscópicas de grado leve, sin atrofia bursal y sin afectar los parámetros productivos ocasionados por el desafío con la cepa clásica F52/70 del virus de Gumboro.

\section{Literatura Citada}

1. Ashraf S. 2005. Studies on infectious bursal disease virus. PhD Thesis. Ohio, USA: Ohio State University. 118 p.

2. Banda A. 2011. Aspectos esenciales para el control de la enfermedad de- 
Gumboro. Programa de vacunación. Tipos de vacunas y vías de aplicación. En: VI Seminario Internacional de la Asociación de Médicos Veterinarios Especialistas en Aves 2011. Perú: AMEVEA.

3. Butcher G, Miles R. 1995. Infectious bursal disease (Gumboro) in commercial broilers. University of Florida IFAS Extension. 3 p. [Internet]. Available in: http://edis.ifas.ufl.edu/vm024

4. Carballeda J, Zoth S, Gómez E, Gravisaco M, Berinstein A. 2011. Activation of the immune response against infectious bursal disease virus after intramuscular inoculation of an intermediate strain. Immunobiology 216 (Suppl 9): 1028-1033. doi: 10.1016/ j.imbio.2011.03.003

5. Di Fábio, J. 2006. Situación de la enfermedad de Gumboro en Brasil. En: Libro blanco de la enfermedad de Gumboro. España: Laboratorios Hipra. p 71-74.

6. Eterradossi N, Saif Y. 2013. Infectious bursal disease. In: Saif Y (ed). Diseases of poultry. $13^{\text {th }}$ ed. USA: Iowa State Press. p 219-246.

7. Etienne F. 2002. Strategies de prevention de la maladie de Gumboro dans les elevages semi-industriels de la región de Dakar, Senegal. Tesis de Médico Veterinario. Toulouse, Francia: Universidad Paul Sabatier. $82 \mathrm{p}$.

8. Giambrone J. 1987. Evaluación y relaciones morfométricas en la enfermedad infecciosa de la bursa como método de diagnóstico. The American Association of Avian Pathology. Georgia, USA. Bull Tech 23: 24-38.

9. González R, Silveira E, Olazábal E. 2005. Frecuencia y caracterización de lesiones anatomo-patológicas en la enfermedad de Gumboro y enfermedades secundarias asociadas en nuestras condiciones ambientales. Estudio retrospectivo. REDVET 6(10). [Internet]. en: http://www.veterinaria.org/revistas/ redvet/n101005/100503.pdf
10. Guadarrama A, Castellanos L, Cubillas C. 2009. Comparación de la inmunidad conferida por una vacuna de infección de la bolsa de Fabricio entre las estirpes Hy-line e Isa Brown. En: México: Reunión de la Asociación Nacional de Especialistas en Ciencias Avícolas de México (ANECA).

11. Guzmán J, Alba M, Icochea E, Manchego A, Perales R, Fribourg S. 2010. Evaluación del complejo vacunal antígeno-anticuerpo de la enfermedad de Gumboro administrado in ovo en pollos de carne frente a un desafío experimental con la cepa F52/70. Rev Inv Vet Perú 21:210-218.

12. Harris J. 2010. Characterization of infectious bursal disease viruses isolated from commercial chickens. PhD Thesis. Delaware, USA: University of Delaware. $132 \mathrm{p}$.

13. Jackwood D. 2009. Current status of infectious bursal disease. En: México: Reunión de la Asociación Nacional de Especialistas en Ciencias Avícolas de México (ANECA).

14. Nielsen O, Sorensen P, Hedemand J, Laursen S, Jorgensen P. 1998. Inflammatory response of different chicken lines and B haplotypes to infection with infectious bursal disease virus. Avian Pathol 27: 181-189. doi: 10.1080/03079459808419321

15. Perozo F, Villegas P, Fernández R, Cruz J, Pritchard N. 2009. Efficacy of single dose recombinant Herpesvirus of turkey infectious bursal disease virus (IBDV) vaccination against a variant IBDV strain. Avian Dis 53: 624-628. doi: 10.1637/8687-31009RESNOTE. 1

16. Perozo F, Villegas $P$, Mavárez $Y$, Fernández R, Cruz J. 2010. Eficacia de un herpesvirus de pavo recombinante expresando la proteína VP2 del virus de la enfermedad de Gumboro ante un desafío experimental. Rev Cient LUZ 20: 132-137. 
17. Rauw F, Lambrecht B, Van Den Berg T. 2007. Pivotal role of ChIFN $\gamma$ in the pathogenesis and immunosuppression of infectious bursal disease. Avian Pathol 36: 367-374. doi: 10.1080/03079450701589159

18. Saif Y. 2003. Vacunas y vacunación contra la enfermedad de Gumboro. Guía Anual 2003. Mundo Vet 43: 7-8.

19. Saif Y. 2006. Tipos antigénicos del virus de la enfermedad de Gumboro. En: Libro blanco de la enfermedad de Gumboro. España: Laboratorios Hipra. p 21-25.

20. Sarachai C, Chansiripornchai $N y$ Sasipreeyajan J. 2010. Efficacy of infectious bursal disease vaccine in broiler chickens receiving different vaccination programs. Thai J Vet Med 40: 9-14.

21. Sharma J, Kim I, Rautenschlein S, Yeh H. 2000. Infectious bursal disease virus of chickens: pathogenesis and immunosuppression. Dev Comp Immunol 24: 223-235. doi: 10.1016/ S0145-305X(99)00074-9

22. Skeeles B. 2001. Score de lesiones bursales. Georgia: Laboratorios SheringPlough. 2 p.

23. Van der Berg T, Gonze M, Meulemans G. 1991. Acute infectious bursal disease in poultry: isolation and characterisation of a highly virulent strain. Avian Pathol 20: 133-143. doi: 10.1080/03079459108418748

24. Van der Berg T. 2000. Acute infectious bursal disease in poultry: a review. Avian Pathol 29: 175-194. doi: 10.1080/ 03079450050045431

25. Villegas P. 2009. Enfermedad de Gumboro: situación mundial y control futuro. En: XXI Congreso Latinoamericano de Avicultura. La Habana, Cuba: Asociación Latinoamericana de Avicultura. 